\title{
Enlargement of Neural Foramina and Dynamic Stabilization in Spondylolisthesis without Restoring the Alignment: Technical Note
}

\author{
Ali Fahir Ozer ${ }^{1}$, Tuncer Suzer ${ }^{1}$, Mehdi Sasani $^{2}$, Tunc Oktenoglu ${ }^{2}$ Emrah Egemen ${ }^{3}$ \\ ${ }^{I}$ Department of Neurosurgery, Koc University School of Medicine, Istanbul, \\ ${ }^{2}$ Department of Neurosurgery, American Hospital, Istanbul, \\ ${ }^{3}$ Department of Neurosurgery, Koc University Hospital, Istanbul, Turkey
}

It is well known that the cause of radiculopathy is the compression of the nerve root within the foramina which is narrowed secondary to sliding of the corpus and reduced disc height. In some patients, unroofing the foramen does not resolve this problem. We described a new decompression technique using pedicle removal and transpedicular dynamic instrumentation to stabilization the spine. We performed this operation in 2 patients and achieved very good results.

Key Words: Spondylolisthesis • Dynamic stabilization $\cdot$ Lumbar pedicle $\cdot$ Neural foraminal stenosis

\section{INTRODUCTION}

In patients who have degenerative spondylolisthesis and isthmic spondylolisthesis with low slipping rate, radicular symptoms occur secondary to narrowed neural foramina. Nerve roots are extremely compressed between the pedicle and posterior part of the corpus vertebra ${ }^{10)}$. Moreover, disc height reduction leads to more severe stenosis.

Classically restoring of disc height and alignment of the spine with rigid instrumentation provides a normal foraminal space and nerve root compression findings may improve ${ }^{6,9)}$. However, this procedures need to fusion of the segment and decreased motion in the spine. In elderly patient these operations have some potential risks such as pseudoarthrosis, adjacent segment disease and infection. Moreover, to achieve a fusion might not be possible in those old patients if there is accompanying osteoporosis. We also know that if the patient has no sign of sagittal balance problem, it is not necessary to restore the alignment of the spine with a major surgery as spinal fusion.

We know that new technologies lead new surgical techniques as motion preservation in lumbar spine. The dynamic instrumentation systems allow enough stabilization while pre-

- Received: December 2, 2015 • Revised: January 11, 2016

- Accepted: January 13, 2016

Corresponding Author: Ali Fahir Ozer, MD

Department of Neurosurgery, Koc University School of Medicine,

Rumelifeneri Yolu Sariyer, Istanbul 34450, Turkey

Tel: +90-212-338-1401, Fax: +90-212-338-1559

E-mail: alifahirozer@gmail.com

@This is an open access article distributed under the terms of the Creative Commons Attribution Non-Commercial License (http://creativecommons.org/licenses/by-nc/4.0/) which permits unrestricted non-commercial use, distribution, and reproduction in any medium, provided the original work is properly cited. venting fusion-related complications. In this technical note, we describe to create a wide neural foramen with pedicle removal to decompress the nerve roots and dynamic instrumentation for stabilization of spine. We performed this operation in 2 patients with spondylolisthesis. Surgical decompression technique in this article is also suitable for performing the dynamic stabilization to prevent pseudoarthrosis.

\section{CASE REPORT}

\section{Illustrative Case}

A 45-year-old woman was admitted with complaints of back and both leg pain for 6 months. The patient does not feel pain in lying position. However when she attempts to walking, she feels severe pain on her buttocks and legs. Neurologic examination was normal.

Magnetic resonance imaging (MRI) scan and computed tomography (CT) revealed grade II spondylolisthesis at L5S1 level. The disc height was severely decreased and Modic changes were also observed. Both L5 nerve roots were compressed in narrowed foramens (Fig. 1). The compression of nerve roots between the vertebral corpus with disc remnants and L5 pedicle was also shown in diagram (Fig. 2). There was not any sign of coronal imbalance on X-ray of the patient. We performed our decompression and stabilization technique and the patient was discharged 3 days after surgery without any complaints.

\section{Surgical Technique}

The patient was operated in prone position with the general anesthesia. Operation level was determined with fluoroscopy. 


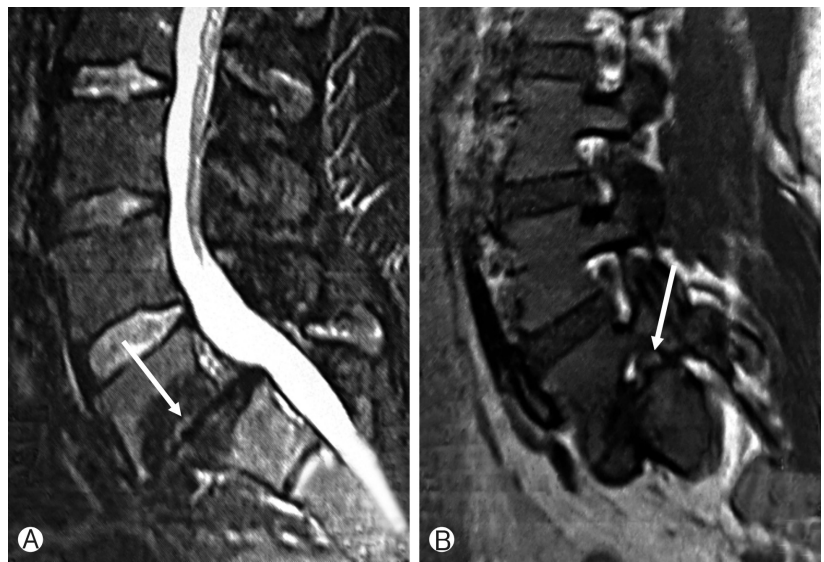

Fig. 1. The sagittal magnetic resonance imaging scans disclose degenerative changes and nerve root compression. Arrow indicates collapsed disc space (A) and foraminal nerve root in the stenotic neural foramen (B).

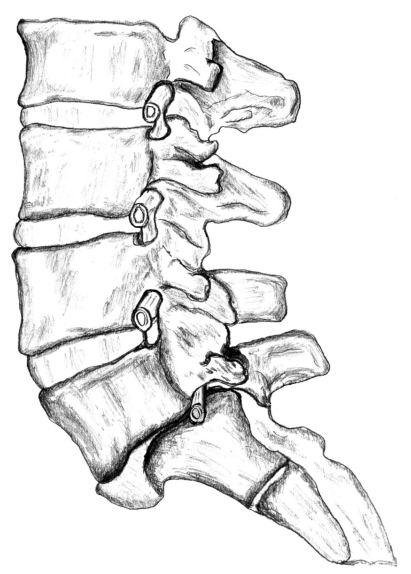

Fig. 2. A diagram is describing the compression of nerve roots between the vertebral corpus with disc remnants and L5 pedicle.

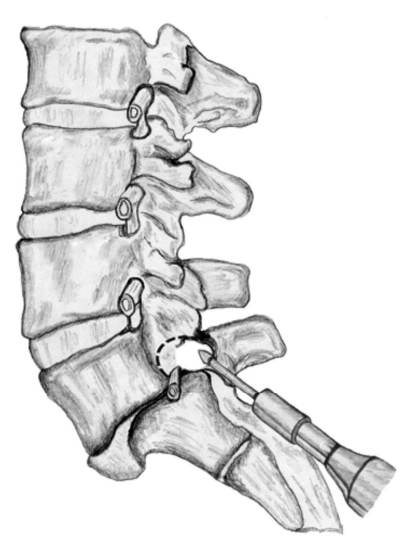

(A)

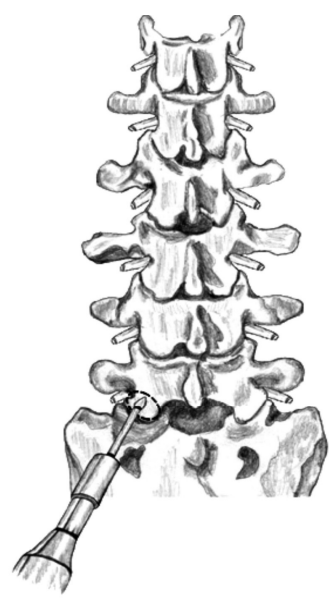

Fig. 3. The removal of the bone to create an enlarged foramina is drawn in the diagram. (A) Lateral view. (B) Posterior anterior view.

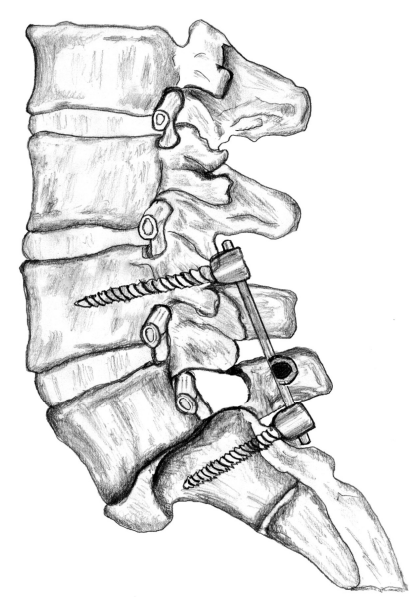

Fig. 4. Dynamic transpedicular instrumentation provides sufficient support to stabilize the translational deformity.

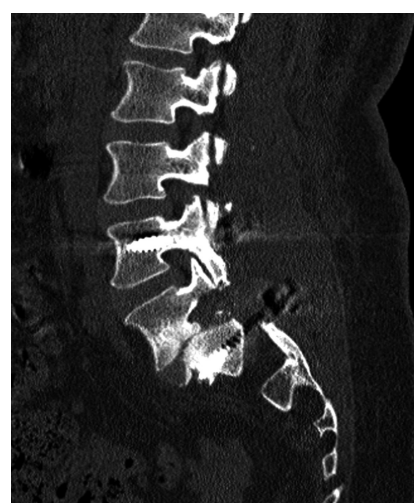

Fig. 5. A computed tomography scan after surgery disclosed enlarged foramina after pedicle removal.

Midline skin incision was performed and L5 lamina was exposed following bilateral paravertebral muscle dissection. The L5 lamina was removed and bilateral L5 and S1 nerve roots were explored. Gill's procedure was considered ineffective for this patient because L5 nerve roots were extremely compressed between the vertebral corpus with disc remnants and L5 pedicle bilaterally ${ }^{4,5}$. The L5 pedicles were removed with high speed drill using the surgical microscope and a new and large fora men was created between L4 and S1 pedicles (Fig. 3). Then, nerve roots were replaced in this enlarged area. Osteotomy was not considered since there was no spinal balance problem. Moreover, L4-S1 bilaterally dynamic stabilization was performed and operation was completed (Fig. 4). A postoperative CT scan disclosed the created enlarged neural foramina (Fig. 5).

\section{DISCUSSION}

Spondylolisthesis is one of the reasons of low back and leg pain with most often compression of L4, L5, and S1 nerve roots $^{7}$.

The nerve root compression within the foramina is the main problem in patients with spondylolisthesis who has radicular signs. Especially in patients who have degenerative spon- 
dylolisthesis or low-grade dysplastic type spondylolisthesis, foraminal stenosis gets worse in time due to disruption of the disc. The volume of the foraminal space starts to decrease when sliding of vertebra begins, and this decrease gets worse in time with destruction of the disc ${ }^{2,8}$. Thus, all these changes lead to pain and numbness after the decrease of foraminal volume and compression of the nerve root.

In this techniquLe, removing of the pedicles in both sides will give extra place to the nerve roots via additionally unroofing the neural foramens. The removal of the lamina and inferior facet joints together with the pedicle leads to decompression of both upper and lower nerve roots.

In patients who have degenerative spondylolisthesis or spondylolisthesis with low severity index, stabilization can be provided using with any transpedicular dynamic stabilization systems if they have spontaneous fusion in slipped segment. The pedicles of the L4 vertebra are used for screw insertion for patients who have L5-S1 spondylolisthesis.

In classical approach, to restore the disc height and realignment of the motion segment with Interbody fusion and posterior transpedicular instrumentation may solve the problem. We know that, in elderly patient these operations have potential risks as pseudoarthrosis, infection and adjacent segment disease. The presence of osteoporosis is also a problem to achieve a solid fusion in those patients. Moreover, if the patients have no balance problem in both degenerative spondylolisthesis and low-dysplastic developmental spondylolisthesis, restoration of the alignment is not necessary. In these patients, the nerve roots still get crushed in the foramens, and the problem still persists even sometimes worsens. It is known that, spontaneous fusion occurs between the bodies of vertebra over the years in some patients. Gill's procedure has been proposed in such cases, however only unroofing the foramens do not resolve the problem because of the compression between the pedicle, and posterior part of thevertebra ${ }^{1)}$.

The fusion surgery is also suitable in these patients after pedicle and facet removal for decompression. However, this is a simple and safe operation when one compares with fusion procedures. Advantages of this technique are early mobilization, less painful period and participation in social life in a short time. Hospital cost is also low than fusion operations. The dynamic stabilization instead of fusion also prevents the risks pseudoarthrosis and adjacent segment disease in these patients ${ }^{3}$. We believe that this procedure is suitable as an alternative surgical technique in patients who have degenerative spondylolisthesis or low-grade dysplastic type spondylolisthesis with radicular signs secondary to nerve root compression in decreased neural foramina.

\section{CONCLUSION}

The decrease in disc height causes compression of nerve root in neural foramen and this leads clinical symptoms. The drilling of pedicle increases neural foraminal height therefore allows nerve root decompression. The application of posterior dynamic stabilization to support posterior tension band together with decompression procedure offers the optimal physiologic treatment modality.

\section{CONFLICT OF INTEREST}

No potential conflict of interest relevant to this article was reported.

\section{REFERENCES}

1. Arts M, Pondaag W, Peul W, Thomeer R: Nerve root decompression without fusion in spondylolytic spondylolisthesis: longterm results of Gill's procedure. Eur Spine J 15:1455-1463, 2006

2. Arts MP, Verstegen MJ, Brand R, Koes BW, van den Akker ME, Peul WC: Cost-effectiveness of decompression according to Gill versus instrumented spondylodesis in the treatment of sciatica due to low grade spondylolytic spondylolisthesis: a pro spective randomised controlled trial [NTR1300]. BMC Musculoskelet Disord 9:128, 2008

3. Eser O, Gomleksiz C, Sasani M, Oktenoglu T, Aydin AL, Ataker $\mathrm{Y}$, et al: Dynamic stabilisation in the treatment of degenerative disc disease with modic changes. Adv Orthop 2013:806267, 2013

4. Gill GG, Manning JG, White HL: Surgical treatment of spondylolisthesis without spine fusion; excision of the loose lamina with decompression of the nerve roots. J Bone Joint Surg Am 37-A:493-520, 1955

5. Gill GG, White HL; Surgical treatment of spondylolisthesis without spine fusion. a long term follow-up of operated cases. Acta Orthop Scand Suppl Suppl 85:5-99. 1965

6. Hoppe S, Schwarzenbach O, Aghayev E, Bonel H, Berlemann $\mathrm{U}$ : Long-term outcome after monosegmental 14/5 stabilization for degenerative spondylolisthesis with the dynesys device. J Spinal Disord Tech [Epub ahead of print], 2012

7. Oh CH, Ji GY, Jeon JK, Lee J, Yoon SH, Hyun DK: Slip reduction rate between minimal invasive and conventional unilateral transforaminal interbody fusion in patients with low-grade 1sthmic spondylolisthesis. Korean J Spine 10:232-236, 2013

8. Pawar AY, Hughes AP, Sama AA, Girardi FP, Lebl DR, Cammisa FP: A comparative study of lateral lumbar interbody fusion and posterior lumbar interbody fusion in degenerative lumbar spondylolisthesis. Asian Spine J 9:668-674, 2015

9. Schulte TL, Ringel F, Quante M, Eicker SO, Muche-Borowski C, Kothe R: Surgery for adult spondylolisthesis: a systematic review of the evidence. Eur Spine J [Epub ahead of print], 2015

10. Steiger F, Becker HJ, Standaert CJ, Balague F, Vader JP, Porchet $\mathrm{F}$, et al: Surgery in lumbar degenerative spondylolisthesis: indications, outcomes and complications. a systematic review. Eur Spine J 23:945-973, 2014 